\title{
IMPACT OF REFERENCE CENTER ON BREAST CANCER IN CAPITAL CITY
}

\author{
Vinicius C. P. Santos¹, Sarah R. Santos¹, Daniel B. de Sousa¹, Edras A. F. Souza1', Fernando C. R. Pinheiro \\ ${ }^{1}$ Faculdade de Medicina, Universidade Federal de Goiás - Goiânia (GO), Brazil.
}

Objectives: The purpose of this article is to review the impact of a reference center on breast cancer in the capital city of Goiás. Methodology: The search for articles related to the topic was carried out in platforms such as SciELO and PubMed using the descriptors: reference center, breast cancer, and capital. For the condition of choice, the period of publications of the articles used was 2009-2019. In addition, data from the National Cancer Institute (INCA, acronym in Portuguese) for the year 2018 were used. Results: In the analyzed articles, breast cancer corresponds to 20,828 surgeries, 37,000 hospitalizations, 831,759 chemotherapy procedures, and 43,939 radiotherapy sessions in Brazil. According to INCA's estimates for 2018, the incidence of breast cancer in women was $48.68 \%$ and $72.17 \%$, respectively in Goiás and Goiânia. Thus, in addition to primary prevention, it is necessary screening this pathology through complementary tests (secondary prevention) to diagnose and early treatment, with the aim of reducing mortality. Mammography is the ideal exam for screening for breast cancer by allowing the detection of lesions in their early stages. Conclusion: Therefore, we see from these data that the presence of these increasingly specialized centers in large cities is fundamental, in order to have the best diagnosis and treatment of breast cancer. It was with this objective that the Advanced Breast Diagnostic Center was inaugurated in the Clinical Hospital of Federal University of Goiás in 2016. It has mammography and ultrasound equipment and is the first unit in Midwest to provide a mamotomy to patients of the Unified Health System. This device performs a biopsy, without having to go to the operating room, and decreases the diagnosis time and cost. 